\title{
Applying passive design strategies: case study of an art gallery
}

\author{
I. I. AbuZayed, I. Hashim \& H. Taleb \\ Sustainable Design of the Built Environment, \\ British University in Dubai, UAE
}

\begin{abstract}
This study is a look at passive design strategies which are best suited for the climate of the United Arab Emirates. Through the implementation of a variety of strategies a comfortable internal climate of approximately $23^{\circ} \mathrm{C}$ for approximately six months of the year was achieved. The strategies which were implemented were interlinked to ensure they worked together in a cohesive manner. Colour, shading and windows were incorporated to help minimise heat gain throughout the year. The key strategies of wind and sun, which were managed through a wind tower and solar tubular daylight system, proved to be challenging. The wind tower was helpful in reducing indoor temperatures while increasing ventilation. The daylight technique, although beneficial in theory, could not be measured through a systematic approach. This study confirms that passive design has attainable gains through analysing effects on a functioning building in the UAE.

Keywords: passive design, shading, energy consumption, IES software, wind tower, tubular day lighting, climate control, integrated design, orientation, sustainability.
\end{abstract}

\section{Introduction}

Over the past 30 years the United Arab Emirates has been considered a leading country in its region. It has grown from simple and humble Bedouin settlements to what is now one of the most international economic centres in the world. With this great growth and great boom, however, comes great responsibility. Unfortunately the developers and engineers at that time were either unaware or chose not to look at the long term effects of such growth. This was a growth which was not studied or strategised around. Unfortunately green and sustainable 
structures became a concern long after the majority of the country's developments had taken place.

It is easy to look back over the past 30 years and regret some of the decisions that were taken. Instead we need to learn from the mistakes which were made and come up with a way to help make changes to the built environment as well as placing regulations on new structures.

We are able to learn about the ability of the country's structural and passive techniques by glancing at homes which were constructed during earlier days; homes which made it possible for families to inhabit the country through the use of passive design techniques. The Al Bastakiya area, which has now become renowned for its passive techniques, is a great example of such an area. There is no suggestion that we limit ourselves to the passive design techniques which were utilised in the past. On the contrary we must take the lessons of the past and adapt and develop them with a newer and more advanced perspective. Our technical and comprehensive knowledge, coupled with these techniques, can help in developing new strategies which will incorporate both ideologies to help maximise the efficiency of passive homes. We should not ignore the developments our ancestors made and start from scratch. To the contrary, we must pick up where they left off with the help of our technical ability and international outlook.

\section{Literature review}

According to Designing Buildings collaborative [1], 'passive design maximizes the use of natural sources of heating, cooling and ventilation to create comfortable conditions inside the building' [2]. In order to determine the passive design strategies best suitable for the United Arab Emirates, first a study of the local climate must be done.

Through the use of the climate consultant software it was observed through temperature range analysis that the UAE experiences a very hot and humid climate. According to the Canadian Centre for Occupational Health and Safety, thermal comfort is achieved when a person is able to perform their daily tasks while wearing a normal amount of clothing. Thermal comfort effects a person's productivity and health. On average a commercial, office setting has a thermal comfort temperature of $21-23^{\circ} \mathrm{C}$ [3]. The comfort zone within any space ranges from $21-23^{\circ} \mathrm{C}$ and the average annual mean UAE temperature is $27^{\circ} \mathrm{C}$. Therefore the UAE's high temperatures will be a key challenge in reaching thermal comfort within the passively designed interior of an art gallery. There are eight months in the year where climatic conditions are above comfort levels. The winter months of January, February, March and December fall within the comfort range [4].

When reviewing ground level temperature parameters, it is important to note that the surface of the ground can easily absorb solar rays and heat gain throughout the day, but underground temperatures absorbs less heat based on the depth to which you dig. Therefore in July, which is one of the hottest months of the year, the average is approximately $35^{\circ} \mathrm{C}$. At a depth of 0.5 metres the temperature is $32^{\circ} \mathrm{C}$. At a depth of 2 metres the temperature is $28^{\circ} \mathrm{C}$ and at a depth of 4 metres 
the temperature is $26^{\circ} \mathrm{C}$. Therefore, by choosing to go beneath ground level, the structure of a building can benefit from the offset of cooler earth qualities.

Through the Climate Consultant software another interesting analysis which allows us to learn about local climatic characteristics is the dry bulb temperature. There is a high concentration of temperature increases between the hours of 0630 to 1700 and there is an even higher concentration of heat gain between 0900 and 1600 . Additionally, $53 \%$ of temperature measurements are over $27^{\circ} \mathrm{C}$. This shows us that the majority of heat gain from within the UAE comes from solar radiation. Therefore solar radiation and its possible offset of heat gain is the key challenge in order to minimise heat gain within the passively designed art gallery.

The 2013 analysis of the wind velocity within the UAE remains within the mean value of $3.5 \mathrm{~m} / \mathrm{s}$ throughout the year. Although this velocity is not very high, it is still important to make the most of it [5]. This requires a strategy to capture available wind flow and utilise it in a way which ensures that the building's interior comfort level and ventilation standards are met. The implemented strategy must be located on the north-west end of the structure which will allow it to penetrate the most air coming from that direction into the building interior. As noted in the site plan, the north-west end of the building occupies empty land and this will help in supplying a greater amount of wind.

Overall when looking at the psychometric chart, it is easy to see that the majority of the weather conditions throughout the year in the UAE fall outside of the comfort zone. Through the implementation of passive design strategies we hope to increase comfort level within the art gallery to a higher percentage. As noted earlier, the main challenge is solar heat gain. Therefore the design, orientation and solar lighting techniques for the building need to be carefully studied and developed in order to obtain the required sunlight without the heat gain which accompanies it.

Another factor is underground temperature, which can be exploited to the benefit of the building. This element is found within the UAE and underground levels within the building can help extract these cooler temperatures from the earth in order to utilise them.

Additionally, wind capture and ventilation strategies for the building must be used carefully in order to ensure that there is a maximum amount of air circulation and ventilation occurring within the gallery.

Due to the highly humid atmosphere, the use of water within and around the structure will not be incorporated. Evaporative cooling strategies could prove to be beneficial in reducing the temperature and could also bring about extra and unneeded humidity. This humidity may affect comfort within the gallery as well as damaging the canvases and art work on display.

Currently the climate of the UAE offers climatic comfort $17 \%$ of the time; meaning that there are just 62 days of the year which offer an all-round comfortable environment. The objective of this study is to increase this number through the use of passive design strategies. Now that we better understand the climatic challenges within the UAE and there is a better outlook in terms of the key factors needed, we can move on to the design development of the building. 


\section{Methodology}

\subsection{Orientation}

One of the main strategies in sustainable design is the orientation of a building. This will help in optimising solar and wind aspects which are required targets and therefore used as an advantage. As seen from the UAE's marine wind assessment, prevailing winds come in from the north-west. It is therefore important to establish an entry point through which wind can enter the space.

\subsection{Light colour}

Structures need to be enveloped with a light coloured material. The use of a light colour will minimise the heat gain reached through solar penetration. Another strategy which can be implemented to a building exterior is coating with a mixture of gypsum and limestone, a mixture which is recommended due to several factors. Initially it was noted that this finishing was utilised in older homes in the Bastakiya area and that this gypsum and lime stone mixture carries with it certain positive thermal qualities. The gypsum material is found all over the UAE, making it a locally sourced material. Gypsum is able to cool itself in a hot climate by outputting moisture when it becomes hot, allowing the material to be almost dynamic and self-cooling. The addition of limestone to the mixture helps add to the strength of the material. This coating on the building exterior enhances passive design elements as well as helping it be in harmony with the architectural heritage of the region.

\subsection{Earth cooling}

For many years, architects and designers alike have been utilising underground thermal properties to their benefit. An example of this is, former sportsman, Gary Neville's house located in Greater Manchester (Shankleman). The home is almost completely submerged underground utilising the earth's thermal qualities in order to minimise the energy used within the space.

This same principle can be employed within the UAE. Although in Gary Neville's home it was in used order to enhance heat gain from the earth's temperature. Structures within the UAE can exploit the underground thermal qualities to minimise heat gain and receive cooler penetration through underground walls.

Geothermal energy uses the same principles of that of the underground building strategies. It is able to capture the difference between the outdoor temperature and underground temperature which in turn minimises the amount of energy consumed [6].

Geothermal energy system has been commonly employed in cold climates with the aid of a heat pump in order to extract energy from the source. In this design, however, the geothermal passive cooling system will be implemented without the use of much mechanical aid. The objective is to use a geothermal cooling system to cool water being used within the building via the earth's thermal qualities. This 
will remove any need for a water cooling system throughout the summer months. In contrast to this, the water will also be heated during the winter months, s due to the stable thermal quality of the earth [7].

A closed loop geothermal system allows water to go underground and release or obtain energy, depending on the season, then re-enter the building at a much more comfortable temperature which can be directly felt by visitors.

\subsection{Open loft-like interior}

Through the use of an open loft-like interior, visitors to the space can enjoy two main factors. The first is the comfort of having visual continuity within the space, allowing the space to psychologically be more pleasant for visitors.

Additionally through the open loft-like interior, ventilation and cross ventilation can occur within the space (Image 9.4). This increases the amount of air entering and exiting the space at the same time, benefiting overall indoor air quality.

\subsection{Shading and window strategies}

Building exteriors are angled or tapered slightly outwards in order to shade the lower levels. This was a strategy that helps by creating shading all around the building and every single window without disturbing the visual appearance of the building exterior, in addition to allowing an appropriate amount of solar penetration into the building. This was calculated using the VSA of the hottest day of the year. The calculation offered the need for $0.8 \mathrm{~m}$ shading required all around [8]. In order to ensure maximum shading, the tapered exterior was made to reach one metre, ensuring maximum shading.

In addition to the shading techniques, windows are to be placed on the western and eastern ends designed in a horizontal manner and placed at the upper end of every floor. This design technique ensures that lower sun is able to penetrate into the structure. This lower angled sun, also referred to as the winter sun, carries with it the properties of sunlight with less heat gain. This achieves one of the main objectives, ensuring light penetration within the space, but at a rate which does not interrupt internal thermal comfort.

\subsection{Modern wind tower}

Another element which can be implemented within the design can be directly extracted from the UAE's architectural heritage. A wind tower is a method of capturing air and bringing it into the building. This method was been able to provide a means of thermal comfort when adapted almost fifty years ago in the Bastakiya area. It is therefore an interesting element which can be adapted into a sustainable design.

The orientation of the tower is important to capture the wind in a manner that can help in reducing temperatures and enhancing indoor air quality. In addition to this, the southern and north eastern ends of the triangles will be equipped with a scoop exhaust fan which will help in sucking out hot air which rises and pushing 
it out of the building. This simple mechanism will then pull air into the wind tower from the outside, enhancing the amount of air entering the space.

\subsection{Tubular daylight device}

Daylight is an important element to incorporate within any sustainable design. The tubular daylight device extends from the ceiling to the lowest level carrying through natural daylight from the roof. The tubular daylight device will be centrally located within the space in order to maximise the solar penetration.

In order to avoid unnecessary heat gain, the device should incorporate an automated cap on the roof which can be closed it if necessary. Additionally the daylight device itself will carry a matt finish and a controllable shutter. This will ensure that heat gain from the device can be controlled and completely based on the needs of the occupants, allow the design to be flexible in meeting their needs.

\section{Results}

\subsection{IES simulation and analysis}

In order to conclude that the passive design of the building is effective the various scenarios were analysed using the Apache simulator in IES to compare their data. To achieve the most reliable data it was necessary to analyse different settings, keeping in mind the main parameters such as climate and the use of passive elements of the building. Thermal data is an important tool in understanding building temperature that reflects the comfort levels generated for the occupant or end user. This factor allows the best understanding of structural function via passive cooling.

Energy consumption comparisons of the building allow us to determine whether it is necessary to consume all the energy throughout the year or whether there are months where we can make some exceptions. Through the application of passive design strategies it was determined that when looking at one of the cooler months of the year $\left(15^{\text {th }} \mathrm{Dec}\right)$, there was a maintained temperature of $25^{\circ} \mathrm{C}$. Therefore it is safe to conclude that usage of AC during the winter months will be rare to none and that comfort levels may be achieved without AC.

The wind tower is an essential tool for the design of the building in that it provides cooler air within the building and helps to reach comfort level in the rooms. To analyse the use of the wind tower it was essential to simulate the difference of air temperature on the ground floor with and without the tower. The results indicate an increase in air temperature of the room by about $1.5^{\circ} \mathrm{C}$ to $2^{\circ} \mathrm{C}$ without the wind tower. Total energy consumed with the $\mathrm{AC}$ on for the whole year accounts to $96.1 \mathrm{MWh}$, whereas in the summer months between April and September alone, electricity consumption is calculated at 55.2 MWh. These calculations are as per the IES simulation.

The summer months alone use more than half of the energy consumption - 55.2 $\mathrm{MWh}$. If the AC system is not used during the winter months then yearly savings of energy are $40.9 \mathrm{MWh}$. 


\section{Analysis and discussion}

\subsection{Wind tower}

The wind tower has proven to be an important aspect of the building as the temperature within the room increases without it. Even in some of the summer months passive cooling is achieved due to the wind tower. It is therefore possible to just use ventilation and not necessarily use the air conditioning systems. Considering other buildings in Dubai without wind towers, a comfortable air temperature can be maintained with just the use of a fan especially during the winter.

\subsection{Energy output}

The energy consumption of this building can be reduced especially during the winter months. Even in the summer the use of AC can be reduced. These results are evidence that cooling strategies in Dubai consume more energy than required. The parameters for this project were set for cooling at a constant of $23^{\circ} \mathrm{C}$ for less than half a year, so the winter months can be spent comfortably without the AC.

\section{Conclusion}

The design of a completely passive building within the UAE can seem like an unimaginable task. It has proven to be a challenge to try and utilise all of the passive strategies within the building in order to achieve the thermal comfort levels required. Through the implementation of all of these strategies it was possible for almost half of the year, mostly during the cooler months, to ensure that the internal comfort level reached the desired $23^{\circ} \mathrm{C}$.

The strategies implemented were those which were interlinked and connectively incorporated in order to ensure these results. The orientation of the building and minimising of the surface area was a key determining factor in the design. After this, the colour, shading and windows added to the design played a key role in minimising heat gain throughout the year. The key strategies of wind and air, which were managed through the wind tower and solar tubular daylight system did face some challenges. The wind tower played a great role in reducing indoor temperatures and helping with the ventilation of the building. The daylight technique, although beneficial in theory, could not be measured through a systematic approach. To the contrary, the parameters which were developed around the daylight technique such as the cap, matt finish and shutters will definitely be of aid in controlling the penetration of sunlight as desired.

Overall, passive design was able to provide thermal comfort for a period of time in which UAE structures usually rely on mechanical cooling. Therefore the overall objective was reached. 


\section{References}

[1] British University in Dubai, 2010. Hydroelectric Energy. (Exercise) November 2010 ed BUID: British University in Dubai.

[2] British University in Dubai, 2012. Week 4 VSA Exercise. (Exercise) October 2012 ed BUID: British University in Dubai.

[3] Canadian Centre of Occupational Health and Safety 2013. Thermal Comfort for Office Work. (Online). Available at: http://www.ccohs.ca/oshanswers/ phys_agents/thermal_comfort.html.

[4] Climate Consultant Software 2013. United Arab Emirates Climate Conditions. (Online) Available at: http://climate-consultant.software .informer.com/5.4/.

[5] Dubai Coast Zone. 2012. (Online) Available at: http://www.dubaicoast.ae/ (August 24th 2012).

[6] Designing Buildings Wiki 2015. Passive Building Design. (Online) Available at: http://www.designingbuildings.co.uk/wiki/Passive_building_design.

[7] Gary Neville House 2012, Business Green. (Online) Available at: http://www.businessgreen.com/bg/news/2199538/gary-neville-and-marsscrap-wind-turbine-plans-despite-councils-green-light.

[8] Geothermal Heating and Cooling 2012. Green Passive Solar Magazine. (Online) Available at:_http://greenpassivesolar.com/sustainable-renewableenergy/geothermal-energy/. 